\title{
Sputum interleukin-25 correlates with asthma severity: a preliminary study
}

\author{
Magdalena Paplińska-Goryca, Elżbieta M. Grabczak, Marta Dąbrowska, Joanna Hermanowicz-Salamon, \\ Małgorzata Proboszcz, Patrycja Nejman-Gryz, Marta Maskey-Warzęchowska, Rafał Krenke
}

Department of Internal Medicine, Pulmonary Diseases and Allergy, Medical University of Warsaw, Warsaw, Poland

Adv Dermatol Allergol 2018; XXXV (5): 462-469

DOI: https://doi.org/10.5114/ada.2017.71428

\begin{abstract}
Introduction: Interleukin 25 is an epithelial-derived cytokine associated with allergic Th2 inflammation. However, little is known about the role of IL-25 in different asthma phenotypes and its relationship with disease severity. Aim: To evaluate and compare the mRNA and protein expression of IL-25 in patients with mild-to moderate/severe asthma and cough variant asthma (CVA).

Material and methods: Thirty-eight patients with stable asthma (11 patients with mild-to-moderate asthma, 14 patients with severe asthma and 13 patients with CVA) and 14 control subjects were enrolled. IL-25 protein concentration was measured in induced sputum (IS) supernatants by ELISA and IL-25 mRNA expression was evaluated in IS cells by real time PCR.

Results: No differences in IS IL-25 mRNA and IL-25 concentration between controls and the whole asthma group were found. In the detailed analysis, a lower IL-25 mRNA expression in sputum cells was observed in severe asthma compared to CVA and controls. IL-25 protein concentration in sputum supernatants was elevated in patients with severe asthma compared to controls, CVA and mild-to-moderate asthma. A sputum IL-25 level was increased in atopic vs. non-atopic asthma patients. The elevated IL-25 mRNA expression and protein concentration was associated with a lower eosinophil and higher neutrophil percentage in asthmatic airways.

Conclusions: Our results suggest that IL-25 is particularly associated with severe asthma. The relationship between IL-25 and neutrophilic airway inflammation suggests the pleiotropic role of IL-25 in the immune response in this disease.
\end{abstract}

Key words: interleukin 25, asthma, neutrophils, eosinophils, induced sputum.

\section{Introduction}

Interleukin 25 (IL-25), also known as IL-17E, is a member of a larger IL-17 family. There is evidence that this cytokine is locally produced in the airways and may be involved in airway inflammation in asthma. IL-25 is constitutively produced by bronchial epithelium [1]. Other sources of IL-25 are eosinophils, basophils and mast cells $[2,3]$. Interleukin 25 promotes and augments allergic Th2 inflammation via production of IL-4, IL-5, and IL-13 [4-6]. This results in a high serum IgE concentration, airway eosinophilia and airway hyperresponsiveness (AHR) [7]. The effect of exogenous IL-25 protein on acute inflammatory response in the airways was shown to be dependent of CD4 T cells [6] or mediated by unidentified IL-5 producing cells [8]. Interleukin 25 was shown to act directly on human fibroblasts inducing collagen secretion, blockage of IL-25 inhibits subepithelial fibrosis, mesenchymal cell proliferation and AHR [9]. Thus, IL-25 and other epitheli- um-derived cytokines including thymic stromal lymphopoietin (TSLP) and IL-33 are regarded as prominent markers of allergic response $[10,11]$.

Most data on IL-25 activity available up to date have been derived from studies on animal models. There have been only few human studies evaluating the role of IL-25 in asthma. An increased expression of IL-25 was detected in the asthmatic bronchial mucosa and in the skin of patients with eczema [12]. Allergeninduced expression of IL-25 and its receptor (IL-25RB) in patients with atopic asthma correlated with disease severity [13]. Bronchial IL-25 expression correlated inversely with forced expiratory volume in $1 \mathrm{~s}\left(\mathrm{FEV}_{1}\right)[14]$. In a study which included 43 asthmatics, a higher IL-25 expression in bronchial biopsy samples was associated with greater AHR, increased systemic and airway eosinophilia, more advanced subepithelial thickening, and

Address for correspondence: Marta Maskey-Warzęchowska, Department of Internal Medicine, Pulmonary Diseases and Allergy, Medical University of Warsaw, 1 a Banacha St, 02-097 Warsaw, Poland, phone: +48 22599 25 62, fax: +48 22599 15 60, e-mail: mmaskey@op.pl Received: 21.06.2017, accepted: 13.09.2017. 
elevated expression of Th2 cytokine genes as compared to healthy controls [15].

\section{Aim}

In the face of the scarce data from human studies on the role of IL-25 in asthma, we undertook a study aimed at: 1$)$ the evaluation of IL-25 mRNA expression and protein IL-25 concentration in induced sputum (IS) of asthmatics with different asthma phenotypes and disease severity, 2) the assessment of the relationship between sputum IL-25 expression/level and clinical features of asthma with special regard to cellular phenotypes.

\section{Material and methods}

\section{Study design}

This was a cross-sectional study performed between 2011 and 2015 which involved 38 patients with stable asthma and 14 control subjects. Asthma patients were recruited from the pulmonary outpatient department of the University Hospital in Warsaw. Exclusion criteria for all subjects were disease exacerbation or symptoms of the respiratory tract infection in the previous 3 months and non-effective sputum induction.

The diagnosis of asthma and the evaluation of its severity was made in accordance with the Global Initiative for Asthma (GINA) guidelines [16]. Cough variant asthma (CVA) was diagnosed in patients with cough as the sole symptom lasting for at least 8 weeks, normal spirometry (no airway obstruction) and a positive result of the methacholine challenge. All patients with asthma underwent the following evaluations: medical history, physical examination, spirometry with flow-volume curve, airway obstruction reversibility test (when applicable), methacholine bronchial challenge, allergy skin prick tests and sputum induction. Patients with chronic cough, ultimately diagnosed as CVA, also underwent additional examinations to exclude other causes of chronic cough $[17,18]$. Bronchial obstruction reversibility and airway hyperresponsiveness were tested according to the recommendations of the European Respiratory Society (ERS) and American Thoracic Society (ATS) [19].

The control group comprised of healthy non-smoking subjects with no history of obstructive lung disease or atopy. In this group, spirometry (normal spirometry was mandatory for inclusion) and induced sputum were performed.

Interleukin-25 protein concentration was measured in IS supernatants and IL-25 mRNA expression was evaluated in cells obtained from sputum induction in both investigated groups.

The study protocol was approved by the Institutional Review Board. Informed consent was obtained from all individual participants included in the study.

\section{Sputum induction}

The procedure of sputum induction was preceded by inhalation of $400 \mu \mathrm{g}$ of salbutamol and subsequent pulmonary function testing. After the post-bronchodilator spirometry, the patients inhaled sterile hypertonic saline $(\mathrm{NaCl})$ at room temperature and increasing concentrations (3\%, 4\% and $5 \%$ solutions) via an ultrasonic nebulizer (ULTRA-NEB ${ }^{\text {TM }}$ 2000, DeVilbiss, USA). The duration of each inhalation was $7 \mathrm{~min}$. Spirometry was repeated after each inhalation. The induction was stopped after a decrease in the FEV by at least 20\% from baseline (post bronchodilator) FEV value.

\section{Sputum processing}

Induced sputum was processed immediately on receipt as described by other authors [20]. The volume of the sputum was measured and the plugs were separated and weighed. A freshly prepared $0.1 \%$ solution of dithiothreitol (DTT, Sigma Aldrich, St. Louis, USA) in sterile phosphate-buffered saline (PBS) was added in a volume equal to fourth the weight of the sputum, and the mixture was shaken for $15 \mathrm{~min}$. Subsequently, a double volume of sterile PBS was added and the mixture was vortexed briefly. After filtration through $70 \mu \mathrm{m}$ nylon cell strainer (Falcon, Corning Brand, NY, USA), the sputum was centrifuged for $10 \mathrm{~min}$ at $1800 \mathrm{~g}$. The cells were counted in Neubauer hemocytometer, the percentage of dead cells and epithelial cells (squamous and ciliated) was assessed. The total number of cells $\left(\times 10^{6}\right)$ and total cell count $\left(10^{6}\right.$ cells/g sputum) was calculated. The pellet of cells was suspended in RNAlater solution (Qiagen, Valencia, USA) and stored at $-80^{\circ} \mathrm{C}$ for further investigation. The smears were stained with May-Grünwald-Giemsa staining. The criteria for appropriate IS quality were as follows: less than 50\% of epithelial cells (squamous and ciliated), and more than 300 non-epithelial cells on one slide.

\section{RNA isolation and cDNA synthesis}

Total RNA was isolated from IS cells using Nucleo Spin RNA II Columns Kit (Machery\&Nagel, Düren, Germany). The concentration and purity of isolated RNA was measured on a spectrophotometer (Beckman DU650, Krefeld, Germany). Fourteen $\mu$ l of total RNA underwent reverse transcription using SuperScript III First-Strand Synthesis Super Mix for qRT-PCR (Thermo Fisher, Waltham, USA).

\section{Real-time quantitative PCR}

Real-time quantitative PCR evaluation was performed with an ABI-Prism 7500 Sequence Detector System (Applied Biosystems, Foster City, USA). For real-time PCR, $0.8 \mu \mathrm{l}$ of cDNA was amplified in $16 \mu \mathrm{l}$ of PCR volume, containing a Power SYBR Green PCR mastermix (Thermo Fisher, Waltham, USA) with $150 \mathrm{nM}$ of specific primers. 18s rRNA was applied for each sample as an internal control in order to normalize gene expression levels. Sequences of the applied primers were as follows: IL-25: forward 5'-TG- 
GTCCCTTTTTGGGAAACC-3' reverse 5'-TGTGCAGAAGTGCAGGCTTT-3' (153bp), 18s rRNA: forward 5'-GGATGAGGTGGAACGTGTGAT-3', reverse 5'-AGGTCTTCACGGAGCTTGTTG-3' (148 bp). Each sample was measured in duplicate. The results were expressed as relative quantification units (fold change).

Relative quantification values were calculated by the $2^{-\Delta \Delta C T}$ method. For endogenous control, 18s rRNA was used. In the calculation, cycle thresholds (CTs) of the cDNA of sputum cells from patients with asthma and controls were calibrated with the average CTs of sputum cells from healthy volunteers.

\section{Protein concentration measurement}

The total IgE concentration was evaluated using ELISA BioMerieux mini Vidas (Marcy-l'Étoile, France) according to the manufacturer's instructions. The measurements of IL-25 concentrations in sputum supernatants were performed with ELISA kit (EIAab, Wuhan, China) according to the manufacturer's instructions. The mean minimal detectable level of the test was $10 \mathrm{pg} / \mathrm{ml}$.

\section{Ethical approval}

All procedures performed in this study were in accordance with the ethical standards of the institutional and/or national research committee and with the 1964 Helsinki declaration and its later amendments or comparable ethical standards.

\section{Statistical analysis}

Sample size estimation was based on data from an earlier study by Seys et al. [21]. We assumed that the difference between sputum IL-25 mRNA expression in asthma and controls which should be detected, would be similar to the results reported by these authors. To detect the difference with $t$ test with a power of $80 \%$ and a significance level of $5 \%$ and standard deviation value similar to those reported in the paper by Seys et al., the sample size was estimated as 28 asthma patients.

Statistical analysis was performed with the use of Statistica 12.0 software package (StatSoft Inc., Tulsa, OK, USA). Differences between categorical and continuous variables were tested using Pearson $\chi^{2}$ test or nonparametric Mann-Whitney $U$ test. Results are given as median and interquartile range (IQR). Correlations between variables were analyzed with Spearman's rank test. Differences were considered statistically significant at $p<$ 0.05. Receiver-operating characteristic (ROC) curves were constructed and the area under ROC curve (AUC), sensitivity and specificity were calculated the best cut-off values for IL-25 mRNA expression and protein level in IS.

\section{Results}

\section{Patient characteristics}

Baseline patient characteristics are presented in Table 1. Thirteen asthmatics were classified as CVA (34\%), mild-to-moderate asthma was diagnosed in 11 (29\%) patients and the remaining 14 (37\%) patients were classified as severe asthma.

Twenty (53\%) patients were treated with a combination of inhaled corticosteroids (ICS) (median dose of $800 \mu \mathrm{g}$ of budesonide or equivalent (IQR: 640-1000 $\mu \mathrm{g}$ )

Table 1. Demographic, clinical data and cellular composition of induced sputum (IS) (the sum of all non-epithelial cells was counted as $100 \%$ ) of patients with asthma and control subjects

\begin{tabular}{|c|c|c|c|}
\hline Parameter & $\begin{array}{l}\text { Controls } \\
(n=14)\end{array}$ & $\begin{array}{l}\text { Asthma } \\
(n=38)\end{array}$ & $P$-value \\
\hline Gender (male/female) & $7 / 7$ & $6 / 32$ & 0.012 \\
\hline Age [years] & $38(34-40)$ & $52(41.5-60)$ & 0.006 \\
\hline $\mathrm{BMI}\left[\mathrm{kg} / \mathrm{m}^{2}\right]$ & $23.3(21.5-25.4)$ & $28.2(24.3-30.8)$ & 0.063 \\
\hline Positive skin prick-tests $(n)$ & NA & 20 & NA \\
\hline Total IgE [IU/ml] & NA & $61.5(16.4-210)$ & NA \\
\hline Never smokers/ex-smokers/current smokers ( $n)$ & $12 / 2 / 0$ & $28 / 7 / 3$ & 0.1034 \\
\hline Disease duration [months] & NA & $132(24-246)$ & NA \\
\hline $\mathrm{FEV}_{1}(\%$ predicted $)$ & 105 (101-120) & $83(69-96)$ & $<0.001$ \\
\hline Epithelial cells (\%) & $14(12-21)$ & $22(18-27)$ & 0.028 \\
\hline Macrophages (\%) & $33(26-54)$ & $36(24-46)$ & 0.827 \\
\hline Lymphocytes (\%) & $6(4-7)$ & $6.5(3-9)$ & 1.000 \\
\hline Neutrophils (\%) & $55(43-66)$ & $50(41-59)$ & 0.330 \\
\hline Eosinophils (\%) & $1(0-1)$ & $3(2-7)$ & $<0.001$ \\
\hline
\end{tabular}

$B M I$ - body mass index, FEV - forced expiratory volume at 1 s, FVC - forced vital capacity, NA - not applicable, IS - induced sputum. Values expressed as median and IQR; $p$-value obtained by Pearson $\chi^{2}$ test or Mann-Whitney $U$ test. 
and long acting $\beta_{2}$-agonists (LABA), while 18 (47\%) patients received only short-acting $\beta_{2}$-agonists (SABA) as needed.

The cellular composition of IS in asthmatics and controls is shown in Table 1. The percentage of epithelial cells and eosinophils was significantly higher in the asthma group compared to healthy controls.

\section{IL-25 mRNA expression and protein concentration in induced sputum}

No differences between controls and asthma analyzed as a summarised group were found in mRNA: 1.09 (0.1-8.04) fold change vs. 0.46 (0.06-3.06) fold change for controls and asthmatics, respectively. Also, both groups did not differ in IL-25 protein level: 314.9 (237.6418.5) pg/ml vs. 399.2 (320.6-585.9) pg/ml in controls and asthmatics, respectively.

The analysis of IL-25 mRNA expression and protein concentration in asthma subgroups stratified according to disease severity showed a lower IL-25 mRNA expression in sputum cells in patients with severe asthma - 0.095 (0.03-0.46) fold change compared to controls (1.09 fold change, IQR: 0.1-8.04 fold change), and CVA (0.85 fold change, IQR: 0.22-18.7 fold change). In contrast, IL-25 protein concentration in sputum supernatants was significantly higher in these patients $(571.2 \mathrm{pg} / \mathrm{ml}$, IQR: 451-633.8 pg/ml) than in controls $(314.85 \mathrm{pg} / \mathrm{ml}$, IQR: 237.6-481.5 pg/ml), CVA (386.5 pg/ml, IQR: 327.3-446.1 $\mathrm{pg} / \mathrm{ml}$ ), and mild-to-moderate asthma (340.6 pg/ml, IQR: 267.1-407.5 pg/ml) (Figure 1).

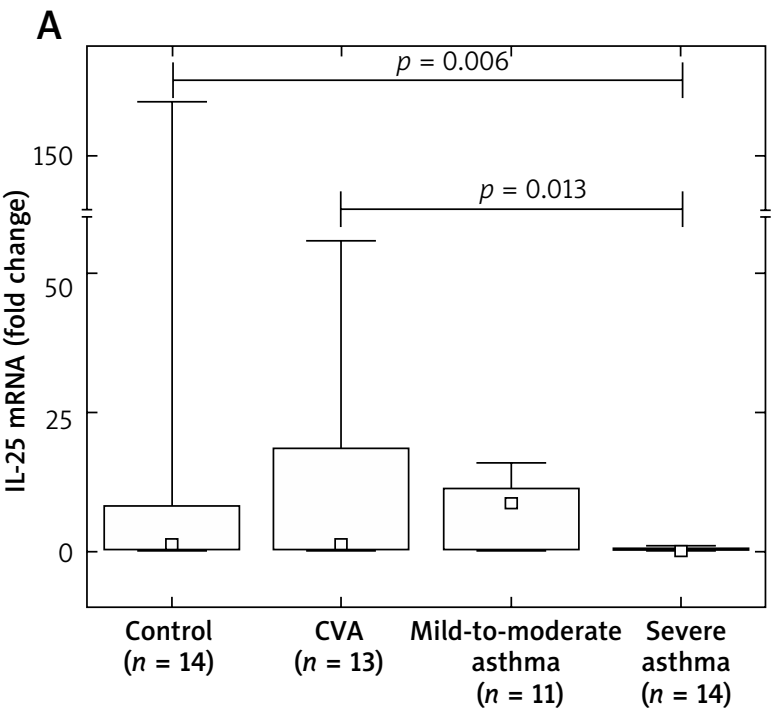

a Median $\square 25-75 \%$ I Min.-max.
ROC analysis of the discriminative value of sputum IL-25 mRNA and IL-25 protein levels in differentiation between controls and asthma

According the ROC analysis, the diagnostic accuracy of IL-25 in the differentiation between asthmatics and controls was low. Both, IS IL-25 mRNA expression and protein concentration showed low sensitivity and specificity in the discrimination between healthy subjects and asthma patients. The optimal cut-off points for IL-25 were: 0.76 fold change for mRNA expression (sensitivity: $66 \%$, specificity: $50 \%, A \cup C=0.598$ ) and $289 \mathrm{pg} / \mathrm{ml}$ for protein concentration (sensitivity: $81 \%$, specificity: $50 \%$, AUC = 0.618).

The analysis of asthma patients sub-classified according to the cut-off values obtained from ROC analysis showed a significantly lower percentage of IS eosinophils, shorter disease duration and higher $\mathrm{FEV}_{1} / \mathrm{FVC}$ ratio in the group of patients with a high IL-25 mRNA expression ( $\geq 0.76$ fold change). An increased sputum neutrophil percentage was observed in the group of asthmatics with sputum IL-25 concentration $\geq 289 \mathrm{pg} / \mathrm{ml}$ (Table 2).

\section{IL-25 mRNA and protein expression in the analysis} of clinical features of asthma

In a separate analysis of asthma patients stratified according to the IS eosinophil percentage, an elevated IL-25 mRNA expression was associated with non-eosinophilic sputum phenotype (eosinophil concentration <3\%) (Table 3).

In the analysis of clinical features of the disease, we found that neither IL-25 mRNA expression nor IL-25 pro-

\section{B}

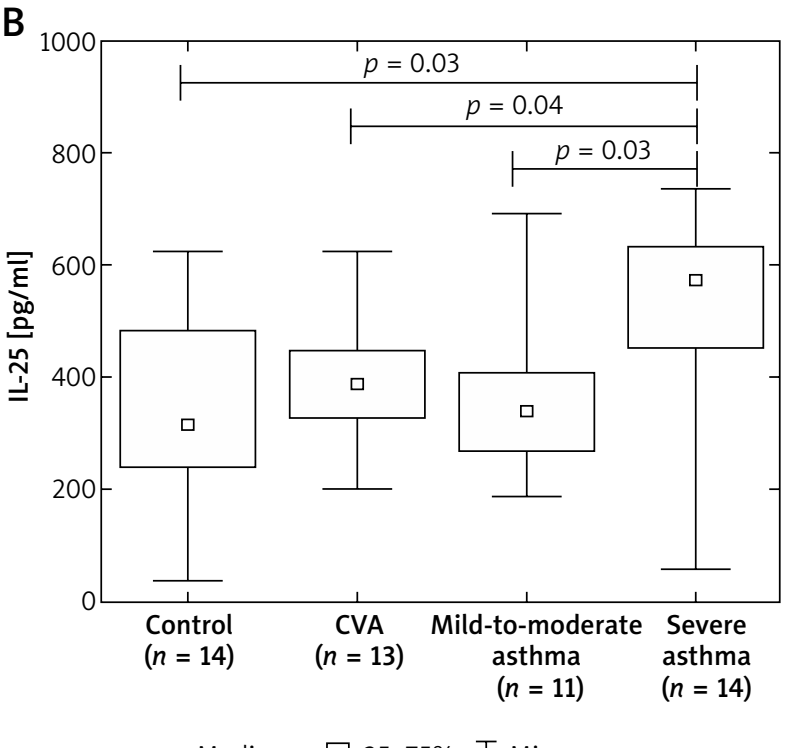

口Median $\square$ 25-75\% I Min.-max.

Figure 1. Box plots of the IL-25 mRNA expression in cells from induced sputum (A) and IL-25 protein concentration in induced sputum supernatants (B) from patients with asthma and control subjects. Comparisons were performed using Mann-Whitney $U$-test, significant differences $(p<0.05)$ are shown 
M. Paplińska-Goryca, E. M. Grabczak, M. Dąbrowska, J. Hermanowicz-Salamon, M. Proboszcz, P. Nejman-Gryz, M. Maskey-Warzęchowska, R. Krenke

Table 2. Percentage of sputum eosinophils and neutrophils, disease duration and FEV/FVC ratio in asthma patients sub-classified according to the optimal cut-off points for IL-25 mRNA expression and IL-25 protein concentration obtained from ROC analysis

\begin{tabular}{|c|c|c|c|c|c|c|}
\hline \multirow[t]{2}{*}{ Parameter } & \multicolumn{3}{|c|}{ IL-25 mRNA } & \multicolumn{3}{|c|}{ IL-25 protein } \\
\hline & $\begin{array}{c}<0.76 \text { fold change } \\
(n=27)\end{array}$ & $\begin{array}{c}\geq 0.76 \text { fold } \\
\text { change }(n=13)\end{array}$ & $P$-value & $\begin{array}{c}<289 \mathrm{pg} / \mathrm{ml} \\
(n=8)\end{array}$ & $\begin{array}{c}\geq 289 \mathrm{pg} / \mathrm{ml} \\
(n=30)\end{array}$ & $P$-value \\
\hline Eosinophils (\%) & $5(2-17)$ & $1(0-5)$ & 0.003 & $3(2-24)$ & $3.5(1-7)$ & 0.604 \\
\hline Neutrophils (\%) & $52(38-65)$ & $46(41-54)$ & 0.207 & $30(25-47)$ & $53(43-63)$ & 0.005 \\
\hline $\begin{array}{l}\text { Disease duration } \\
\text { [months] }\end{array}$ & $180(120-300)$ & $72(24-144)$ & 0.04 & $96(10-396)$ & $120(36-216)$ & 0.604 \\
\hline $\mathrm{FEV}_{1} / \mathrm{FVC}$ & $65.5(59.4-72.1)$ & 81 (69-97) & 0.005 & $74.3(60-78.8)$ & $68.9(63-81.2)$ & 0.919 \\
\hline IgE [IU/ml] & $114(14.8-341)$ & $48(18-169)$ & 0.335 & $101(42-440)$ & $53(15-169)$ & 0.240 \\
\hline ICS [ $\mu$ g budesonide] & $640(0-800)$ & $0(0-400)$ & 0.021 & $0(0-1200)$ & $400(0-800)$ & 0.82 \\
\hline
\end{tabular}

Values expressed as median and IQR, $p$-value obtained in Mann-Whitney $U$ test. ROC - receiver-operating characteristic, FEV - forced expiratory volume at $1^{\text {st }}$ s, FVC-forced vital capacity.

Table 3. mRNA expression and protein concentration of IL-25 in IS of asthma patients stratified according to the sputum eosinophil percentage

\begin{tabular}{lccc}
\hline IL-25 & \multicolumn{3}{c}{ Asthma } \\
\cline { 2 - 4 } & $\begin{array}{c}<\% \\
(n=16)\end{array}$ & $\begin{array}{c}\geq 3 \% \\
(n=22)\end{array}$ & $P$-value \\
\hline mRNA (fold change) & $1.9(0.18-15.9)$ & $0.22(0.03-0.74)$ & 0.03 \\
\hline Protein $[\mathrm{pg} / \mathrm{ml}]$ & $395.1(295-470.7)$ & $425.3(327.3-622.8)$ & 0.25 \\
\hline
\end{tabular}

Values expressed as median and IQR, p-value obtained in Mann-Whitney U test. IS - induced sputum.

Table 4. Eosinophil, neutrophil sputum percentage, total IgE serum concentration, IL-25 mRNA expression and protein concentration in induced sputum from asthma patients with and without atopy

\begin{tabular}{lccc}
\hline Parameter & $\begin{array}{c}\text { Non-atopic patients } \\
(n=18)\end{array}$ & $\begin{array}{c}\text { Atopic patients } \\
(n=20)\end{array}$ & $P$-value \\
\hline Eosinophils (\%) & $2(0-5)$ & $5(2-23)$ & 0.043 \\
\hline Neutrophils (\%) & $47(42-57)$ & $52(31-68)$ & 0.864 \\
\hline IgE $[\mathrm{IU} / \mathrm{ml}]$ & $33.5(11.7-56.5)$ & $152(58-341)$ & 0.006 \\
\hline $\mathrm{IL}-25 \mathrm{mRNA}$ (fold change) & $0.6(0.1-11.3)$ & $0.25(0.1-0.7)$ & 0.316 \\
\hline $\mathrm{IL}-25[\mathrm{pg} / \mathrm{ml}]$ & $331.5(261.5-435)$ & $448.8(361.6-605.2)$ & 0.030 \\
\hline
\end{tabular}

Values expressed as median and IQR, $p$-value obtained in Mann-Whitney $U$ test.

tein concentration correlated with disease duration $(r=$ $-0.31, p=0.09$ and $r=0.18, p=0.31$ for mRNA and protein level, respectively), $\mathrm{FEV}_{1}$ expressed as a percentage of predicted value $(r=0.31, p=0.1$ and $r=-0.22, p=0.22$ for mRNA and protein level, respectively) and IgE serum level $(r=-0.13, p=0.46$ and $r=-0.08, p=0.63$ for mRNA and protein level, respectively) in the whole asthma group. Also, no correlations between IL-25 mRNA expression $(r=-0.312, p=0.08)$ and IS IL-25 concentration $(r=0.305$, $p=0.07)$ and the daily ICS dose were found.

When we divided subjects according to their atopic status, we observed an increased IS IL-25 concentration in atopic vs. non-atopic asthma patients: 448.8 (363.6-
609.9) pg/ml vs. 331.5 (262.8-434.7) pg/ml, respectively, $p=0.03$ (Table 4). IL-25 mRNA expression correlated negatively with sputum eosinophil count in both the non-atopic and atopic group and with a total IgE serum concentration. IL-25 sputum concentration correlated positively with sputum neutrophil count in patients with atopy (Table 5).

\section{Discussion}

Our study showed an elevated IS IL-25 concentration in severe asthma with a simultaneous decrease in IL-25 mRNA expression in IS cells. We also demonstrated that the elevated IL-25 mRNA expression and protein concen- 
tration are associated with a lower eosinophil and higher neutrophil percentage in asthmatic airways. Our study confirmed the relationship between IL-25 concentration in IS and the atopic status of asthma patients.

To our knowledge, this is the first study evaluating IS IL-25 concentration in different asthma phenotypes, particularly in CVA and severe asthma. We found that patients with severe asthma were the only subgroup with a significantly increased IS IL-25 level compared to controls. The poor efficiency of IL-25 ROC analysis to discriminate between all asthma patients and healthy subjects may further suggest that IL-25 is particularly associated with only some asthma phenotypes or severity stages. Although we have not found other studies on IS IL-25 that included patients with severe asthma, our results seem to be consistent with data from some previously published articles. This includes an excellent recent review on the role of IL-25 in asthma [22]. Based on data presented in that paper, it might be concluded that IL-25 is involved in the pathogenesis of severe asthma. In the study by Corrigan et al., it has been shown that allergen-induced expression of IL-25 in atopic asthmatics correlates with disease severity [13]. Peripheral blood granulocytes with expressed IL-25 receptor (IL-17RB+ granulocytes and its subset, type 2 myeloid (T2M) cells) were increased in asthma, and correlated with the degree of airflow obstruction [23]. According to the results of a different study evaluating mRNA expression in IS cells, "IL-5, IL-17A, IL-25 high" patients had worse asthma control [21]. These observations were confirmed by the identification of the cluster of "IL-17A, IL-25 and IL-10 high" sputum profile in a subgroup of asthmatics [24]. These patients had increased sputum eosinophils as well as neutrophils and worse lung function parameters. In the context of the above-cited articles, our results can be seen as new data confirming the relationship between IL-25 and more severe asthma course.

The main source of IL-25 are epithelial cells which express IL-25 constitutively [13, 25]. Inflammatory cells, including eosinophils, basophils and mast cells are capable of producing and secreting IL-25 after allergic, viral or parasitic stimulation $[12,25,26]$. In our study, we found a notable discrepancy between IL-25 PCR and ELISA results, with an inverse IL-25 mRNA expression and IL-25 protein concentration in individual subgroups of patients (e.g. low IL-25 mRNA and high IL-25 protein concentration in patients with severe asthma, as well as in those with atopy). We believe this is an interesting observation, even though we are not able to present a convincing explanation for this finding. We may speculate that the discrepancy between IL-25 PCR and ELISA results could be associated with the different biologic materials used to measure IL-25 mRNA expression and IL-25 protein concentration. The protein level was measured in sputum supernatants which contained IL-25 produced by both structural and inflammatory cells, whereas mRNA expression was evaluated in cells isolated from sputum.
Table 5. Correlations between IL-25 mRNA expression and protein concentration in induced sputum from asthma patients with and without atopy and the percentage of sputum eosinophils and neutrophils, total IgE serum concentration

\begin{tabular}{lcccc}
\hline Parameter & $\begin{array}{c}\text { Non-atopic patients } \\
(n=18)\end{array}$ & \multicolumn{2}{c}{$\begin{array}{c}\text { Atopic patients } \\
(n=20)\end{array}$} \\
\cline { 2 - 5 } & $r$ & $p$ & $r$ & $p$ \\
\hline IL-25 mRNA (fold change) & & & & \\
\hline Eosinophils (\%) & -0.62 & 0.02 & -0.57 & 0.02 \\
\hline Neutrophils (\%) & 0.21 & 0.49 & -0.04 & 0.89 \\
\hline IgE [IU/ml] & 0.33 & 0.25 & -0.65 & 0.02 \\
\hline IL-25 protein [pg/ml] & & & & \\
\hline Eosinophils (\%) & 0.47 & 0.08 & -0.81 & 0.46 \\
\hline Neutrophils (\%) & 0.35 & 0.20 & 0.54 & 0.02 \\
\hline IgE [IU/ml] & -0.28 & 0.29 & -0.29 & 0.25 \\
\hline
\end{tabular}

Correlations were performed with Spearman's rank test.

Moreover, we suppose that almost entire inhibition of IL-25 mRNA expression in severe asthma could have been related to ICS treatment received by these patients. All investigated patients with severe asthma $(n=14)$ received inhaled corticosteroids and this treatment is known to reduce the number of eosinophils [27] and to decrease the levels of inflammatory mediators in asthmatic airways [28]. The additional analysis of all asthma patients classified according to ICS treatment (treated, $n=20$, vs. not treated, $n=18$ ) showed a significantly higher IL-25 mRNA expression in those not receiving ICS (0.2 fold change (IQR: 0.04-0.7) and 0.9 fold change (IQR: $0.2-11.3)$, respectively; $p=0.04$ ). An opposite relationship was found for IL-25 protein concentration in those two groups (493 pg/ml (IQR: 343.4-621.85 pg/ml) compared to $369.7 \mathrm{pg} / \mathrm{ml}$ (IQR: 289.3-439.5 pg/ml)) in patients treated and not treated with ICS, respectively $(p=0.02)$. Thus, we cannot exclude that the discrepancy between PCR and ELISA results may be associated with the presence of other corticosteroid insensitive sources of IL-25, e.g. some structural airway cells. Although epithelial and endothelial cells are known IL-25 producers, it might be speculated that there are also other cells releasing IL-25 into the bronchial lumen and that IL-25 production in those cells is not efficiently inhibited by ICS. For example, it has been demonstrated that airway smooth muscle cells of patients with severe asthma are corticosteroid insensitive due to a decreased glucocorticosteroid receptor expression and corticosteroid-mediated attenuation of p65 recruitment to gene promoters [29].

In our study, IL-25 level was increased in IS of atopic asthmatics, but it was not associated with Th2 type of response expressed as a total serum IgE level or increased sputum eosinophil count. Moreover, a higher IL-25 protein concentration was correlated with a higher neutrophil 
percentage in IS. We believe this is an interesting observation. An association of IL-25 with neutrophilic asthma phenotype may confirm the pleiotropic nature of this cytokine. This association has also been observed by other authors. One study showed that IL-25 induced the airway neutrophilic murine model of IL-17A-dependent asthma [30]. In a different mouse model of asthma, IL-25 activated NF- $\kappa B$ and production of CXCL8, which is a strong neutrophil chemoattractant [31]. Garley et al. demonstrated the expression of IL-17RA (receptor for IL-17A) and IL-17RB (IL-25 receptor) on the surface of human neutrophils [32] and Rickel et al. found that the development of IL-25 mediated effects requires the presence of both receptors, IL-17RB and IL-17RA [30]. Interestingly, Petersen et al. showed that IL-25 is associated with steroid resistance in asthma by direct induction of IL-4/IL-13 expression in a granulocytic population, T2M cells [33]. Since steroidresistant asthma is commonly associated with neutrophil predominance, IL-25 may be an important cytokine involved in this type of immune response. We may speculate that the relationship between IS IL-25 level and increased neutrophil percentage found in our study was associated with chemotactic activity of IL-25 resulting in neutrophil recruitment into the airways. On the other hand, it cannot be excluded that IS neutrophilia was associated with the use of ICS. This is because a decrease in the number of eosinophils caused by ICS treatment could result in an apparent increase in the percentage of neutrophils in IS. However, as the percentage of eosinophils in IS is relatively low (compared to other subpopulations of cells), it seems unlikely that its further reduction could have resulted in a significant increase in the percentage of neutrophils.

We are aware about several limitations of the presented study. First, due to the preliminary nature of our research, the study group was relatively small. This refers, in particular, to asthma sub-groups that included asthmatics with different disease features and severity. Second, almost $45 \%$ of patients with asthma were treated with ICS what may affect both the cellular composition of IS and the expression of IL-25 mRNA. Some aspects of this issue have already been discussed above in detail. ICS treatment inhibits eosinophilic inflammation but has no or only a weak anti-inflammatory effect on the neutrophilic phenotype of asthma [34]. However, it should be emphasized that the exclusion of asthmatics treated with ICS would make the evaluation of the severe asthma group in which such treatment is mandatory, impossible. Hence, the inclusion of asthma patients treated with ICS into different studies is also commonly accepted by other authors [35-37]. Third, a more detailed and advanced analysis of IL-25 source in IS is required for proper interpretation of our findings. We believe this could be an interesting field for further exploration of the role of IL-25 in obstructive lung diseases.

\section{Conclusions}

Although IL-25 in IS did not differ between patients with asthma and healthy subjects, our results suggest that IL-25 is particularly associated with severe asthma. The relationship between IL-25 and neutrophilic airway inflammation suggests the pleiotropic role of IL-25 in the immune response in this disease.

\section{Conflict of interest}

The authors declare no conflict of interest.

\section{References}

1. Kouzaki H, Tojima I, Kita H, et al. Transcription of interleukin-25 and extracellular release of the protein is regulated by allergen proteases in airway epithelial cells. Am J Respir Cell Mol Biol 2013; 49: 741-50.

2. Terrier B, Bièche I, Maisonobe T, et al. Interleukin-25: a cytokine linking eosinophils and adaptive immunity in ChurgStrauss syndrome. Blood 2010; 116: 4523-31.

3. Dolgachev V, Petersen BC, Budelsky AL, et al. Pulmonary IL-17E (IL-25) production and IL-17RB + myeloid cell-derived Th2 cytokine production are dependent upon stem cell factor-induced responses during chronic allergic pulmonary disease. J Immunol 2009; 183: 5705-15.

4. Fort MM, Cheung J, Yen D, et al. IL-25 induces IL-4, IL-5, and IL-13 and Th2-associated pathologies in vivo. Immunity 2001; 15: 985-95.

5. Fallon PG, Ballantyne SJ, Mangan NE, et al. Identification of an interleukin (IL)-25-dependent cell population that provides IL-4, IL-5, and IL-13 at the onset of helminth expulsion. J Exp Med 2006; 203: 1105-16.

6. Tamachi T, Maezawa Y, Ikeda K, et al. IL-25 enhances allergic airway inflammation by amplifying a Th2 cell-dependent pathway in mice. J Allergy Clin Immunol 2006; 118: 606-14.

7. Sharkhuu T, Matthaei KI, Forbes E, et al. Mechanism of interleukin-25 (IL-17E)-induced pulmonary inflammation and airways hyper-reactivity. Clin Exp Allergy 2006; 36: 1575-83.

8. Hurst SD, Muchamuel T, Gorman DM, et al. New IL-17 family members promote Th1 or Th2 responses in the lung: in vivo function of the novel cytokine IL-25. J Immunol 2002; 169: 443-53.

9. Gregory LG, Jones CP, Walker SA, et al. IL-25 drives remodelling in allergic airways disease induced by house dust mite. Thorax 2013; 68: 82-90.

10. Divekar R, Kita H. Recent advances in epithelium-derived cytokines (IL-33, IL-25, and thymic stromal lymphopoietin) and allergic inflammation. Curr Opin Allergy Clin Immunol 2015; 15: 98-103.

11. Semlali A, Jacques E, Koussih L, et al. Thymic stromal lymphopoietin-induced human asthmatic airway epithelial cell proliferation through an IL-13-dependent pathway. J Allergy Clin Immunol 2010; 125: 844-50.

12. Wang YH, Angkasekwinai P, Lu N, et al. IL-25 augments type 2 immune responses by enhancing the expansion and functions of TSLP-DC-activated Th2 memory cells. J Exp Med 2007; 204: 1837-47.

13. Corrigan CJ, Wang W, Meng Q, et al. Allergen-induced expression of IL-25 and IL-25 receptor in atopic asthmatic airways and late-phase cutaneous responses. J Allergy Clin Immunol 2011; 128: 116-24. 
14. Corrigan CJ, Wang W, Meng Q, et al. T-helper cell type 2 (Th2) memory T cell-potentiating cytokine IL-25 has the potential to promote angiogenesis in asthma. Proc Natl Acad Sci USA 2011; 108: 1579-84.

15. Cheng D, Xue Z, Yi L, et al. Epithelial interleukin-25 is a key mediator in Th2-high, corticosteroid-responsive asthma. Am J Respir Crit Care Med 2014; 190: 639-48.

16. Global Strategy for Asthma Management and Prevention Available from: www.ginasthma.org. 2016.

17. Stec SM, Grabczak EM, Bielicki P, et al. Diagnosis and management of premature ventricular complexes-associated chronic cough. Chest 2009; 135: 1535-41.

18. Dąbrowska M, Grabczak EM, Arcimowicz M, et al. Causes of chronic cough in non-smoking patients. Adv Exp Med Biol 2015; 873: 25-33.

19. Crapo RO, Casaburi R, Coates AL, et al. Guidelines for methacholine and exercise challenge testing-1999. This official statement of the American Thoracic Society was adopted by the ATS Board of Directors, July 1999. Am J Respir Crit Care Med 2000; 161: 309-29.

20. Hargreave FE, Pizzichini E, Pizzichini M. Induced sputum examination. J Allergy Clin Immunol 1998; 101: 569-70.

21. Seys SF, Grabowski M, Adriaensen W, et al. Sputum cytokine mapping reveals an "IL-5, IL-17A, IL-25-high" pattern associated with poorly controlled asthma. Clin Exp Allergy J Br Soc Allergy Clin Immunol 2013; 43: 1009-17.

22. Yao X, Sun Y, Wang W, et al. Interleukin (IL)-25: pleiotropic roles in asthma. Respirology 2016; 21: 638-47.

23. Li L, Lukacs NW, Schaller MA, et al. IL-17RB(+) granulocytes are associated with airflow obstruction in asthma. Ann Allergy Asthma Immunol 2016; 117: 674-9.

24. Seys SF, Scheers H, Van den Brande P, et al. Cluster analysis of sputum cytokine-high profiles reveals diversity in T(h)2high asthma patients. Respir Res 2017; 18: 39.

25. von Moltke J, Ji M, Liang HE, et al. Tuft-cell-derived IL-25 regulates an intestinal ILC2-epithelial response circuit. Nature 2016; 529: 221-5.

26. Beale J, Jayaraman A, Jackson DJ, et al. Rhinovirus-induced IL-25 in asthma exacerbation drives type 2 immunity and allergic pulmonary inflammation. Sci Transl Med 2014; 6: $256 r a 134$.

27. van Rensen EL, Straathof KC, Veselic-Charvat MA, et al. Effect of inhaled steroids on airway hyperresponsiveness, sputum eosinophils, and exhaled nitric oxide levels in patients with asthma. Thorax 1999; 54: 403-8.

28. Basyigit I, Yildiz F, Ozkara SK, et al. Inhaled corticosteroid effects both eosinophilic and non-eosinophilic inflammation in asthmatic patients. Mediators Inflamm 2004; 13: 285-91.

29. Chang PJ, Michaeloudes C, Zhu J, et al. Impaired nuclear translocation of the glucocorticoid receptor in corticosteroid-insensitive airway smooth muscle in severe asthma. Am J Respir Crit Care Med 2015; 191: 54-62.

30. Rickel EA, Siegel LA, Yoon BR, et al. Identification of functional roles for both IL-17RB and IL-17RA in mediating IL-25-induced activities. J Immunol 2008; 181: 4299-310.

31. Lee J, Ho WH, Maruoka M, et al. IL-17E, a novel proinflammatory ligand for the IL-17 receptor homolog IL-17Rh1. J Biol Chem 2001; 276: 1660-4.

32. Garley M, Jablonska E, Grabowska SZ, et al. IL-17 family cytokines in neutrophils of patients with oral epithelial squamous cell carcinoma. Neoplasma 2009; 56: 96-100.

33. Petersen BC, Budelsky AL, Baptist AP, et al. Interleukin-25 induces type 2 cytokine production in a steroid-resistant
interleukin-17RB+ myeloid population that exacerbates asthmatic pathology. Nat Med 2012; 18: 751-8.

34. Green RH, Brightling CE, Woltmann G, et al. Analysis of induced sputum in adults with asthma: identification of subgroup with isolated sputum neutrophilia and poor response to inhaled corticosteroids. Thorax 2002; 57: 875-9.

35. Peters MC, Mekonnen ZK, Yuan S, et al. Measures of gene expression in sputum cells can identify Th2-high and Th2low subtypes of asthma. J Allergy Clin Immunol 2014; 133: 388-94.

36. Simpson JL, Scott R, Boyle MJ, et al. Inflammatory subtypes in asthma: assessment and identification using induced sputum. Respirology 2006; 11: 54-61.

37. Hastie AT, Moore WC, Meyers DA, et al. Analyses of asthma severity phenotypes and inflammatory proteins in subjects stratified by sputum granulocytes. J Allergy Clin Immunol 2010; 125: 1028-36.e13. 